\title{
SPATIOTEMPORAL LAND USE CHANGE ANALYSIS AND FUTURE URBAN GROWTH SIMULATION USING REMOTE SENSING: A CASE STUDY OF ANTALYA
}

\author{
N. Aslan ${ }^{1, *}$, D. Koc-San ${ }^{2}$ \\ ${ }^{1}$ Akdeniz University, Faculty of Science, Department of Space Sciences and Technologies, 07058, Antalya, Turkey - \\ nagihanuzen@akdeniz.edu.tr \\ ${ }^{2}$ Akdeniz University, Faculty of Architecture, Department of Urban and Regional Planning, 07058, Antalya, Turkey - \\ dkocsan@akdeniz.edu.tr
}

Commission III, WG III/7

KEY WORDS: LULC Change, Urban Expansion, Urban Growth Simulation, Cellular Automata, Artificial Neural Network method

\begin{abstract}
:
The objectives of this study are: to create land-use maps by 5-year interval from 1995 to 2015, to analyse the land use change and urban development, and to estimate future land-use pattern and urban growth for the years: 2030, 2045 and 2060. Antalya, which is the $5^{\text {th }}$ biggest city of Turkey, was selected as study area. In this study, there are basically three stages: (i) preprocessing and preparing additional bands, (ii) spatiotemporal land use detection using image classification and (iii) land use simulation using urban growth models. Firstly, atmospheric correction was applied to the Landsat 5 TM and Landsat 8 OLI images and land-cover indices, ASTER Global Digital Elevation Model (GDEM), and Nighttime data were prepared to use them as additional bands during the classification process. Secondly, Landsat images were classified using Random Forest (RF) machine-learning algorithm. Thirdly, urban simulations were performed for the years 2005, 2010, and 2015 and land-use pattern and urban growth was estimated for the years 2030, 2045 and 2060. The RF classification accuracies range from $84.44 \%$ to $92.82 \%$. The urban areas increased from 49.56 $\mathrm{km}^{2}$ to $96.25 \mathrm{~km}^{2}$ from 1995 to 2015 . The simulation accuracies were computed above $80 \%$. According to the 2030, 2045 and 2060 simulation results, the urban areas were computed as $133.61 \mathrm{~km}^{2}, 148.27 \mathrm{~km}^{2}$ and $156.85 \mathrm{~km}^{2}$, respectively. As a result, it was seen that the urban area of Antalya has almost doubled between the years 1995-2015 and the urban expansion is expected to continue increasing up to 1960 .
\end{abstract}

\section{INTRODUCTION}

People and therefore the populations are in the heart of sustainable development and urbanization, population growth, population ageing, migration trends are important parameters for sustainability and economic and social development (United Nations, Department of Economic and Social Affairs, Population Division, 2019). Globally, more people live in urban areas than in rural areas and by the year 2018, 55\% of the world's population living in urban areas, while this rate is expected to be $68 \%$ by 2050 (United Nations, 2018). Urban population growth is increasing due to the total population growth and the increase in the percentage of urban residents, and these two factors are expected to add 2.5 billion to the world urban population by 2050 (United Nations, 2018). The rapidly increasing world population, the excessive and often uncontrolled urbanization lead many environmental, social and economic problems. Land-Use/Land-Cover (LULC) pattern is important for many urban research areas including urban growth prediction, environmental monitoring, land surface temperature calculation and climate change analysis. Hence, determining the LULC pattern, examining LULC change and estimating the future LULC pattern are the subjects that do not lose their popularity.

Urban growth models simulation and prediction has become imperative for ecosystem conservation and sustainable development (Yao et al., 2015). Urban growth models are tools that used to predict future urban expansion and/or change. Urban growth models such as Cellular Automata (Batty et al., 1999; Torrens, 2003), SLEUTH (Clarke et al., 1997), Logistic Regression (Landis, 1994) or Artificial Neural Network (Pijanowski et al., 2001) are the models used for urban development forecasting based on real situations and urban trends and providing graphical output (Newman et al., 2016). Cellular Automata (CA) is a mathematical model that consists of a lattice of cells that repeatedly update their status taking into account the transition rules and spatial neighborhood (Wolfram, 1984). According to the Aburas et al. (2016), the CA model is one of the most powerful models for urban development simulation and forecasting. MOLUSCE (Modules for Land Use Change Assessment) is a user-friendly and free plugin developed by Asia Air Survey, Ltd for Quantum GIS. This plugin is based on the Monte Carlo CA model approach (Gismondi, 2019). It randomly selects user-defined sample points to be used for model calibration and validation and supports four different modeling methods: (Artificial Neural Network (ANN), Logistic Regression (LR), Multiple Criteria Assessment (MCA) and Weight of Evidence (WoE)). It then computes calibration statistics, generates transition potential maps and simulates based on the Monte Carlo CA model approach (Gismondi, 2019). MOLUSCE was used in this study because it is free and based on CA- modeling.

The objectives of this study are: to create land use maps by 5year interval from 1995 to 2015 , to analyse the land use change

\footnotetext{
* Corresponding author
} 
and urban development, and to estimate future land use pattern and urban growth for the years: 2030, 2045 and 2060. In this study, there are basically three stages: (i) preprocessing and preparing additional bands, (ii) spatiotemporal land use detection using image classification and (iii) land use simulation using urban growth models. In the first stage, initially atmospheric correction was applied to the Landsat 5 TM and Landsat 8 OLI images using DOS1 Atmospheric Correction Module of QGIS software. Then, Normalized Difference Vegetation Index (NDVI), Normalized Difference Build-up Index (NDBI) and Modified Normalized Difference Water Index (MNDWI) were generated for each date. In order to increase the classification accuracy, in addition to these indices, ASTER Global Digital Elevation Model (GDEM), Defense Meteorological Satellite Program/Operational Linescan System (DMSP/OLS) and Visible Infrared Imaging Radiometer Suite Day/Night Band (VIIRS DNB) Nighttime Lights (NTL) data were used as additional bands during the classification process. In the second stage, Landsat images were classified using the Random Forest (RF) machine-learning algorithm. In the third stage of the study, urban simulations were performed for the years 2005, 2010, and 2015 for validating the simulation results by comparing them with classification results. Then, future land use pattern and urban growth were estimated for the years 2030, 2045 and 2060.

\section{STUDY AREA AND USED DATA}

Antalya is one of the most prominent cities of Turkey with its touristic and agricultural properties. Antalya city covers $20723 \mathrm{~km}^{2}$ (Antalya Provincial Culture and Tourism Directorate, 2020). The population of Antalya has increased from about 1.4 million to about 2.5 million from the years 2000 to 2019 (Turkish Statistical Institute, 2020). It is the $5^{\text {th }}$ biggest city of Turkey in terms of population with high urbanization rate and receives millions of tourists every year. The central (Aksu, Dosemealti, Kepez, Konyaalti, Muratpasa) and Serik districts, where the majority of the population live and urban development is observed most, are chosen as the study area. (Figure 1).

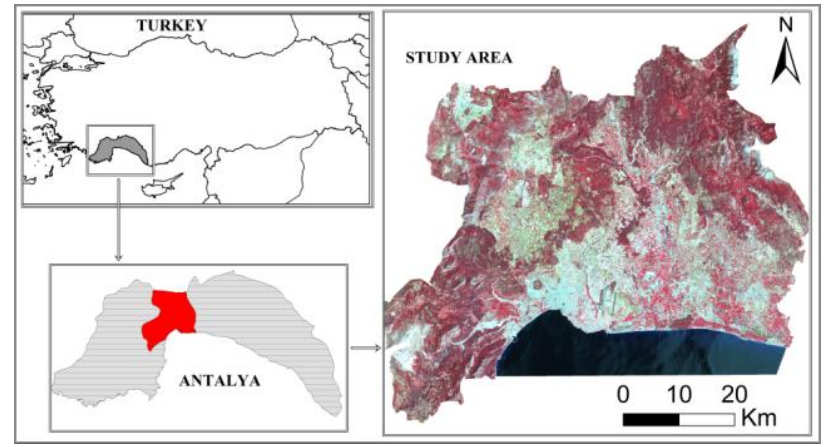

Figure 1. Landsat 8 image of the study area and its location in Antalya in Turkey

Landsat satellites have been presenting the global record of the Earth's surface since the early 1970s. In this study Landsat 5 TM images (July 7, 1995; July 12, 2000; June 24, 2005 and July 24, 2010) and Landsat 8 OLI/TIRS image (July 22, 2015) were used for generating LULC maps. Multispectral bands of Landsat satellites are used and their spatial resolutions are $30 \mathrm{~m}$. Landsat 4-5 TM and 8 OLI / TIRS images were downloaded from United States Geological Survey web site (United States Geological Survey, 2020).
ASTER Global Digital Elevation Model (GDEM), Defense Meteorological Satellite Program/Operational Linescan System (DMSP/OLS) and Visible Infrared Imaging Radiometer Suite Day/Night Band (VIIRS DNB) Nighttime Lights (NTL) data were used as additional bands during the classification process. ASTER GDEM data had been generated by the Ministry of Economy, Trade and Industry (METI) of Japan and United States National Aeronautics and Space Administration (NASA) and the spatial resolution of this digital elevation model is $30 \mathrm{~m}$. DMSP/OLS and VIIRS DNB images are obtained with visible and near infrared sensitive sensors and contain information about light that escapes from the earth at night. DMSP/OLS and VIIRS DNB data are useful in identifying urban and non-urban areas (Gallo et al., 1995) and can be used in urban research, such as urban expansion, energy consumption, population density, disaster assessment, economic assessment, and urban mapping (Elvidge et al. 2007; Ghosh et al. 2010; Chaturvedi et al. 2011, Zhang and Li, 2018; Goldblatt et al., 2018). In addition, slope, population, forest, distance to road, natural protection and agricultural land data were used in simulation processes.

\section{METHODOLOGY}

In this study, there are three stages: (i) preprocessing and preparing additional bands, (ii) spatiotemporal land use detection using image classification and (iii) land use simulation using urban growth models.

In the first stage, initially atmospheric correction was applied to the Landsat $5 \mathrm{TM}$ and Landsat 8 OLI images. Then, NDVI, NDBI and MNDWI were generated for each date. In the second stage, Landsat images were classified using the RF classifier and additional bands. To increase the classification accuracy, ASTER GDEM, DMSP/OLS and VIIRS DNB NTL data were used as additional bands during the classification process. Finally, in the third stage urban simulations were performed for the years 2005, 2010, and 2015 for validating the simulation results by comparing them with classification results. Next, future land use patterns and urban growth models were simulated and estimated for the years 2030, 2045 and 2060. The flow-chart of this study is shown in Figure 2 and processing steps are explained in detail in the following sections.

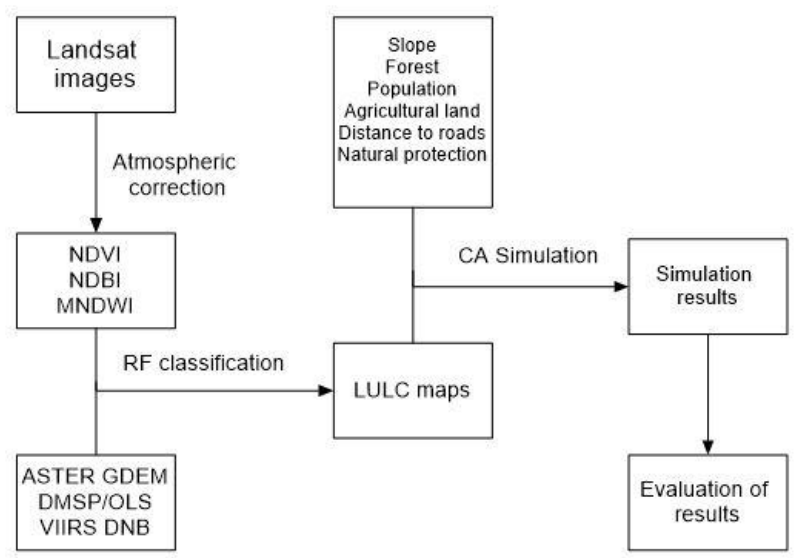

Figure 2. Flow-chart of study 


\subsection{Pre-processing and Preparing Additional Bands and Data}

Initially, Dark Object Subtraction (DOS) atmospheric correction method, DOS1 (Moran et al., 1992) was applied to the downloaded Landsat images with Semi-Automatic Classification Plugin (SCP) of the QGIS software. Later, in order to increase the classification accuracy, NDVI, NDBI and MNDWI indices were created for each date. These indices highlight certain objects in the image and help identify them more easily. While NDVI (Rouse et al., 1974) index is used for especially distinguishing the vegetation, NDBI (Zha et al., 2003; Liu and Zhang, 2011) and MNDWI (Xu, 2006) indices are used for built-up and water areas detection, respectively. NDVI, NDBI and MNDWI indices are calculated using the following equations (Eq.1-3).

$\mathrm{NDVI}=(\mathrm{NIR}-\mathrm{RED}) /(\mathrm{NIR}+\mathrm{RED})$

$$
\mathrm{NDBI}=(\mathrm{SWIR}-\mathrm{NIR}) /(\mathrm{SWIR}+\mathrm{NIR})
$$

\section{MNDWI $=($ GREEN-SWIR $) /($ GREEN + SWIR $)$}

where $\quad$ RED $=$ pixel values of the red band GREEN $=$ pixel values of the green band NIR= pixel values of the near infrared band SWIR= pixel values of the shortwave infrared band

Slope data is derived from ASTER GDEM data using the SLP module of the PCI Geomatics image-processing program. Distance to roads data was created in ArcGIS program using Euclidean Distance method. The population data were downloaded from the official website of Turkish Statistical Institute (Turkish Statistical Institute Central Distribution System, 2020). The population projections for the years 2030 , 2045 and 2060 were estimated with the help of population growth rates data. Forest, agricultural land and natural protection data were provided from Antalya Metropolitan Municipality.

\subsection{Spatiotemporal Land Use Detection using Image Classification}

After the preparation of additional bands, Landsat images were classified using the RF classifier and LULC maps were created to understand the 1995-2015 LULC pattern change and to use them in the simulation process. To increase the classification accuracy, ASTER GDEM and NTL data were used as additional bands during the classification process. DMSP/OLS data is available until 2013. For this reason, DMSP/OLS data were used as an additional band in 1995 to 2010 classifications processes, and VIIRS DNB data was used as an additional band in 2015 classification process. The RF classifier was suggested by Breiman (2001) and it is a machine-learning algorithm. In this study, the RF machine-learning method was applied using Image RF IDL based tool (Aslan and Koc-San, 2015, Koc-San, 2013a, 2013b; Waske et al., 2012). The RF IDL based tool is freely available and license and platform independent (Waske et al., 2012). For classification five LULC classes were determined: urban, vegetation, water, agriculture and other (Figure 3). In the classification process, 100 pixels per class were collected for training, while 500 pixels per class were collected for testing.
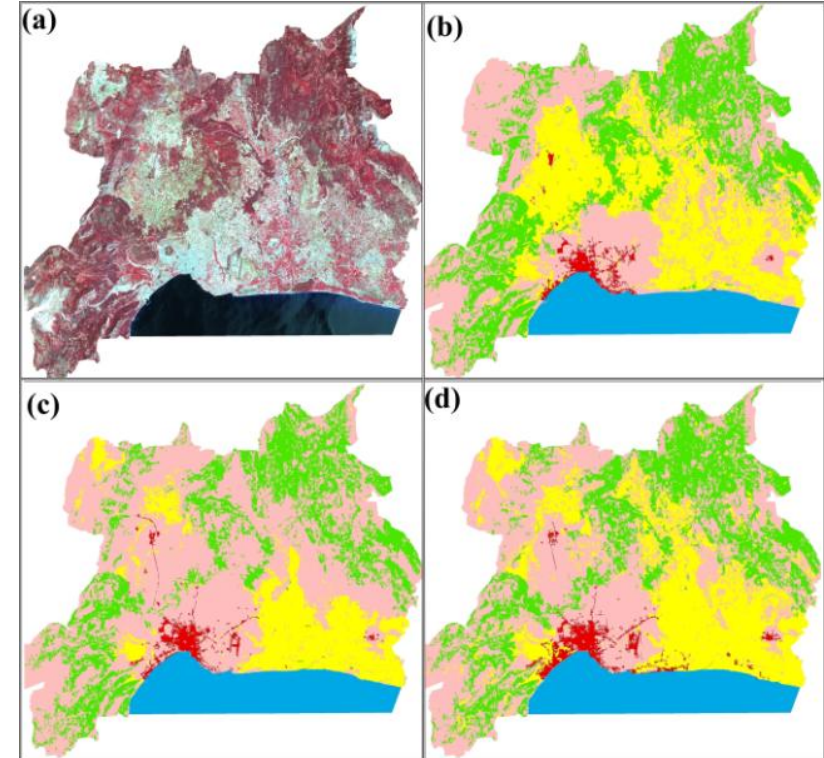

(d)

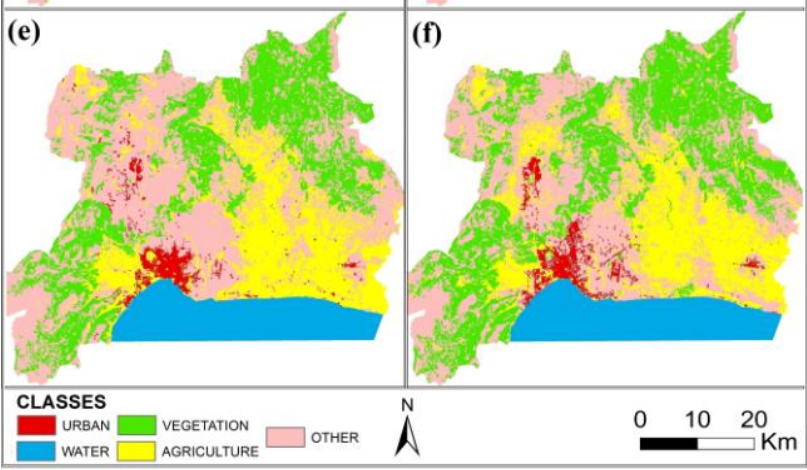

Figure 3. The false color composite of 2015 Landsat image of the study area in (a) and LULC maps; (b) 1995, (c) 2000, (d) 2005, (e) 2010 and (f) 2015

\subsection{Land Use Simulation using Urban Growth Models}

Different methods can be used to predict urban growth. Considering its structure, simplicity and possibility of evolution, the CA model is one of the most powerful models to simulate urban growth (Aburas et al., 2016). In this study, urban growth simulations were produced using the open source GIS software QGIS with plugin MOLUSCE, which use CA urban growth prediction.

The plugin contains different submodules:

(i) Input Submodule can use different biophysical and socioeconomic driving factor data such as temporal land use maps, road network, rivers, topography, population.

(i) With the Area Change Submodule, land use changes can be calculated and LU change transition matrices and land use change maps can be created.

(iii) Sample Data Submodule randomly selects user-defined sample points to be used for model calibration and validation. It supports four modeling methods, which are ANN, LR, MCA and WoE modeling methods.

(iv) The Simulation Sub-Module calculates calibration statistics and creates transition potential maps and simulates based on the Monte Carlo CA model approach.

(v) The Validation Submodule calculates the kappa statistics (standard kappa, kappa histogram and kappa position) that will 
be used to validate the land use maps created by simulation. (Gismondi, 2019).

In this study, both ANN and LR methods were used. Simulations are based on the produced LULC maps. However, the factors such as population, slope, roads, distance to the center also affect the urban development. Therefore, these factors should be included in the simulation. In this study, slope, forest, natural protection areas, distance to roads and agricultural areas layers were used for simulation processes.

First of all, different simulations were made for 2005, 2010 and 2015. Two different LULC maps were used for each model. For example, modeling was performed for 2005 using 1995 and 2000, for 2015 using 1995 and 2005, and the accuracies were assessed for the modeling results using the RF classification results as reference data. According to the calculated kappa values, the simulation results using ANN gave more accurate results than LR. Therefore, 2030, 2045 and 2060 simulations were done using ANN. In this stage, 2000 and 2015 classification images were used to model 2030 urban growth, 2015 classification image and 2030 simulation result were used for modeling 2045 simulation. Finally, 2000 classification image and 2030 simulation results were used for 2060 simulation (Figure 4).

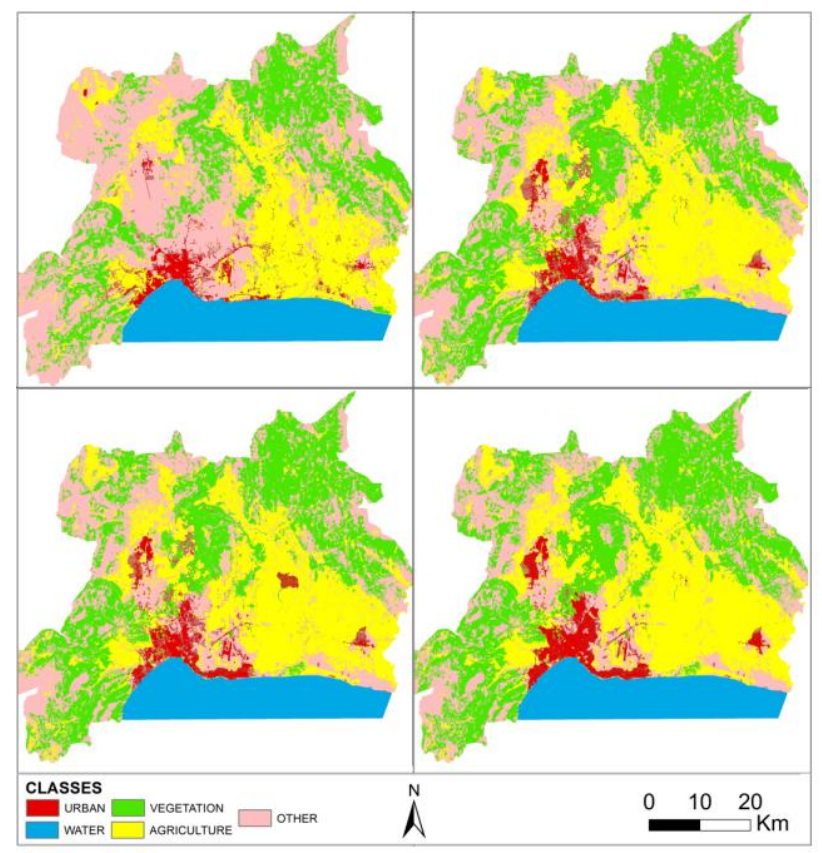

Figure 4. Simulation results; (a) 2015, (b) 2030, (c) 2045 and (d) 2060

\section{RESULTS}

The RF classification accuracies were computed as $84.44 \%$, $88.48 \%, 91.76 \%, 90.84 \%$ and $92.80 \%$ for the years 1995,2000 , 2005, 2010 and 2015, respectively (Table 1). According to the classification results, the urban areas increased from $49.56 \mathrm{~km}^{2}$ to $96.25 \mathrm{~km}^{2}$ from 1995 to 2015 (Table 2). In addition, between the years 1995 and 2015 it was observed that the water areas nearly did not change (about $427 \mathrm{~km}^{2}$ ) while vegetation areas firstly decreased and then increased again. On the other hand, the agricultural areas decreased from $979.99 \mathrm{~km}^{2}$ to $710.46 \mathrm{~km}^{2}$ in 20-year time period.

\begin{tabular}{|l|c|c|}
\hline Years & Overall Accuracy (\%) & Kappa Coefficient \\
\hline 1995 & 84.44 & 0.80 \\
2000 & 88.48 & 0.85 \\
2005 & 91.76 & 0.89 \\
2010 & 90.84 & 0.88 \\
2015 & 92.80 & 0.91 \\
\hline
\end{tabular}

Table 1. RF classification accuracies

The simulation accuracies were computed by comparing the 2005, 2010, 2015 classification and simulation results and computed above $80 \%$. When the computed accuracies were analyzed it can be stated that ANN provides better results than LR in most cases. According to the simulation results, urban area will continue to expand and it is expected to be about $133.61 \mathrm{~km}^{2}$ in $2030,148.27 \mathrm{~km}^{2}$ in 2045 and $156.85 \mathrm{~km}^{2}$ in 2060. In addition, it is estimated that there will be nearly no change in the water areas, while there will be slight changes in vegetation and agriculture areas up to year 2060 (Table 2).

\begin{tabular}{|l|c|c|c|c|}
\hline & \multicolumn{4}{|c|}{ LULC areas $\left(\mathrm{km}^{2}\right)$} \\
\cline { 2 - 5 } & Urban & Vegetation & Agriculture & Water \\
\hline 1995 & 49.56 & 883.46 & 979.98 & 425.92 \\
2000 & 56.02 & 724.65 & 494.63 & 427.17 \\
2005 & 80.43 & 776.90 & 808.33 & 427.11 \\
2010 & 86.38 & 877.91 & 713.77 & 426.43 \\
2015 & 96.25 & 1033.62 & 710.46 & 428.68 \\
2030 & 133.61 & 1023.83 & 1008.79 & 427.91 \\
2045 & 148.27 & 1030.70 & 1020.22 & 427.89 \\
2060 & 156.85 & 1096.01 & 1054.58 & 427.53 \\
\hline
\end{tabular}

Table 2. LULC areas

\section{CONLUSION}

In this study, LULC maps were created by 5 -year intervals from 1995 to 2015 , to analyse the land use change and urban development, and then the future land use patterns and urban growth models for the years: 2030, 2045 and 2060 were predicted. Antalya, which is one of the most prominent cities of Turkey with its touristic and agricultural properties, was selected as study area. According to the obtained results, RF classification accuracies were computed as higher than $84 \%$. In addition, the general kappa values indicate that simulations were quite successful with the values over than $80 \%$. When the study results were analyzed, it is predicted that the urban areas, which have doubled from $49.56 \mathrm{~km}^{2}$ to $96.25 \mathrm{~km}^{2}$ in 2015 , will continue to expand and will be $156.85 \mathrm{~km}^{2}$ in 2060 . In other words, the urban area of Antalya has almost doubled in 20 years (1995-2015) and according to the simulation results the urban expansion is expected to continue increasing in the future. For urban planning and sustainable development, revealing LULC changes and urban expansion trends using urban growth models and conserving protected areas, green areas and agricultural areas with correct plan decisions are important. The results of this study can be evaluated and considered by urban planners and decision makers.

\section{REFERENCES}

Aburas, M.M., Ho, Y.M. Ramli, M.F., Ash'aari, Z.H., 2016. The simulation and prediction of spatio-temporal urban growth trends using cellular automata models: A review, International 
Journal of Applied Earth Observation and Geoinformation, 52, 380-389.

Antalya Provincial Culture and Tourism Directorate, 2020. https://antalya.ktb.gov.tr/TR-66213/genel-bilgiler.html April 2020).

Aslan, N., Koc-San, D., 2015. The usage of combined Landsat 8 imagery and additional bands for random forest classification improvement. Asian Conference on Remote Sensing, 1-9.

Batty, M., Xie, Y., Sun, Z, 1999. Modeling urban dynamics through GIS-based cellular automata. Computers,Environment and Urban Systems, 23(3), 205-233.

Breiman, L., 2001. Random forests. Machine Learning, 45, 532.

Chaturvedi, M., T. Ghosh, L. Bhandari. 2011. Assessing Income Distribution at the District Level for India Using Nighttime Satellite Imagery. In Proceedings of the 32nd AsiaPacific Advanced Network Meeting, 192-217. New Delhi, August 22-26.

Clarke, K., Hoppen, S., Gaydos, L. (1997). A self-modifying cellular automaton model of historical urbanization in theSan Francisco bay area. Environment and Planning B: Planning and Design, 24, 247-261.

Elvidge, C. D., J. Safran, B. Tuttle, P. Sutton, P. Cinzano, D. Pettit, J. Arvesen, C. Small. 2007. Potential for Global Mapping of Development via a Nightsat Mission. GeoJournal 69, 45-53.

Ghosh, T., R. Powell, C. D. Elvidge, K. E. Baugh, P. C. Sutton, S. Anderson. 2010. Shedding Light on the Global Distribution of Economic Activity. The Open Geography Journal, 3, 147160.

Gismondi, M., 2019. MOLUSCCE -An Open Source Land Use Change Analyst, http://2013.foss4g.org/conf/programme/presentations/107/ (29 April 2020).

Goldblatt, R., Stuhlmacher, M.F., Tellman, B., Clinton, N., Hanson, G., Georgescu, M., Wang, C., Serrano-Candela, F., Khandelwal, A.K., Cheng, W.H. Balling Jr., R.C. 2018. Using Landsat and nighttime lights for supervised pixel-based image classification of urban land cover. Remote Sensing of Environment, 205, 253-275.

Koc-San, D., 2013a. Evaluation of different classification techniques for the detection of glass and plastic greenhouses from WorldView-2 satellite imagery. Journal of Applied Remote Sensing, 7, 073553-1-20.

Koc-San, D., 2013b. Thematic mapping of urban areas from WorldView-2 satellite imagery using machine learning algorithms. Journal of Geodesy and Geoinformation, 2, 29- 38.

Landis, J. D.1994. The California urban futures model: A newg eneration of metropolitan simulation-models. Environment and Planning B: Planning and Design, 21, 399-420.

Liu, L. Zhang, Y. 2011. Urban Heat Island analysis using the Landsat TM data and ASTER data: a case study in Hong Kong. Remote Sensing, 3, 1535-1552.
Moran, M., Jackson, R., Slater, P., Teillet, P., 1992. Evaluation of simplified procedures for retrieval of land surface reflectance factors from satellite sensor output. Remote Sensing of Environment, 41, 169-184

Newman, G., Lee, J., Berke, P., 2016. Using the land transformation model to forecast vacant land. Journal of Land Use Science, 11(4), 450-475.

Pijanowski, B., Shellito, B., Bauer, M., Sawaya, K,. 2001: Using GIS, artificial neural networks and remote sensing to model urban change in the Minneapolis St. Paul and Detroit Metropolitan areas. Proceedings of theAme rican Society of Photogrammetry and Remote Sensing Annual Conference, St. Louis, MO.

Rouse, J. W., Haas, R. H., Schell, J. A., Deering, D. W., 1974. Monitoring Vegetation Systems in the Great Plains with ERTS, $3^{\text {rd }}$ Earth Resource Technology Satellite (ERTS) Symposium, 1, 48-62.

Torrens, P. M.,2003. Cellular automata and multi-agent systems as planning support tools. In S. Geertman \& J.Stillwell (Eds.), Planning support systems in practice, (205-222). Aarhus: Springer Berlin Heidelberg.

Turkish Statistical Institute Central Distribution System, 2020, Address Based Population Registration System Results https://biruni.tuik.gov.tr/medas/?kn=95\&locale=tr, $\quad(23$ April 2020).

Turkish Statistical Institute, 2020. Statistical Indicators. http://tuik.gov.tr/UstMenu.do?metod=temelist, (23 April 2020).

United Nations, 2018. World Urbanization Prospects: The 2018 Revision,https://population.un.org/wup/Publications/Files/WUP 2018-KeyFacts.pdf (23 April 2020).

United Nations, Department of Economic and Social Affairs, Population Division ,2019. World Population Prospects 2019: Highlights (ST/ESA/SER.A/423).

United States Geological Survey, 2020. EarthExplorer - Home, https://earthexplorer.usgs.gov/ (23 April 2020).

Xu, H., 2006. Modification of Normalised Difference Water Index (NDWI) to Enhance Open Water Features in Remotely Sensed Imagery. International Journal of Remote Sensing , 27(14) 3025-3033.

Waske, B., van der Linden, S., Oldenburg, C., Jakimow, B., Rabe, A., Hostert, P., 2012. imageRF - A user-oriented implementation for remote sensing image analysis with Random Forests. Environmental Modelling \& Software, 35, 192-193.

Wolfram, S., 1984. Computation theory of cellular automata. Commun. Math. Phys., 96(1), 15-57.

Yao, F.,Hao, C., Zhang, J., 2015. Simulating urban growth processes by integrting cellular automata model and artifical optimization in Binhai New Area of Tianjin, China. Geocarto Int., 1-16.

Zha, Y., Gao, J., Ni, S., 2003. Use of normalized difference built-up index in automatically mapping urban areas from TM 
imagery. International Journal of Remote Sensing, 24(3), 583-594.

Zhang, X., Li, P., 2018. A temperature and vegetation adjusted NTL urban index for urban area mapping and analysis. ISPRS Journal of Photogrammetry and Remote Sensing, 135, 93-111. 